\title{
Analysis of Vibration Attenuation and Energy Consumption of Blasting Demolition Chimney: A Case Study
}

\author{
Shuren WANG, Jiyun ZHANG, Jingtao LI, Fuli KONG, Junqi FAN
}

\begin{abstract}
Demolishing a tall chimney by directional blasting can save time and cost. However, the blasting vibration and the touchdown vibration of the parts of the chimney falling to the ground will cause noise disturbance to the local residents. To reduce the vibration effect of blasting demolition of the chimney, taking the $180 \mathrm{~m}$ high chimney in Jiaozuo, China, as the engineering background, the loose accumulation body with a right-angled trapezoid section 3-6 $\mathrm{m}$ thick was piled with three kinds of graded gravel particles as the buffer layer. According to the site restrictions, the chimney was demolished by directional blasting in two stages. The vibration propagation and attenuation rules of the blasting demolition of the chimney were analyzed and touchdown vibrations of two parts of the chimney were monitored also. Results show that the low frequency vibrations generated by the blasting and chimney touchdown have a greater impact on the surrounding environment. The vibration velocity and energy attenuation represent a form of power function. With the increase of the number of chimney touchdowns, the energy absorption rate of the loose accumulation body becomes lower. The obtained conclusions in this study can provide a reference for the similar blasting demolition practice.
\end{abstract}

Keywords: blasting demolition; chimney; gravel body; vibration velocity

\section{INTRODUCTION}

Demolition of a tall chimney by directional blasting can reduce the amount of construction, save construction time and costs. However, the blasting vibration of the demolition chimney and the touchdown vibration of the parts of the chimney falling to the ground will cause noise disturbance to the local residents.

The blasting vibration wave varies greatly with the density and porosity of the propagation medium [1-2]. The parts of the chimney falling to the ground will display difference characteristics in the absorption of the vibration load by the loose gravel deposits made of different materials [3-4]. It is the currently hot issue to investigate the control techniques of the directional blasting vibration.

Therefore, the loose gravel deposit was constructed as a buffer layer for the demolition chimney falling to the ground, the attenuation characteristics of the blasting vibration were monitored in this study. Based on theoretical calculations and field measurements, the attenuation factor was proposed to analyze the variation rules of the vibration wave propagation and energy attenuation. The results are of a reference value to the similar practice.

\section{STATE OF THE ART}

Aiming at the ground vibration activity, Bose et al. studied the vibration isolation efficiency of the vibration damping trench and loosely stacked gravel, and they found that the depth of the trench played a decisive role, the lowdensity loose gravel stack was sensitive to the vibration isolation effect [5]. Majumder \& Ghosh also made some studies on the channel size and the weakened effect on the stress wave's propagation by the loose gravel deposits [6]. Azzam et al. found that the lateral deformation was effectively controlled by filling the trench of the foundation with polystyrene (EPS) to block the wave propagation path [7]. Vivek \& Sitharamet studied the vibration reduction effect of the particle size of the loose crushed stone [8]. Yu et al. obtained an empirical formula for determining the attenuation effect of stress waves through impact tests by using coral sand as the propagation medium [9]. Based on genetic algorithms, Rafiee-Dehkharghani et al. studied the attenuation law of stress waves as they propagated in pores and loose gravel bodies and they found that the influencing factors formed a complex function [10]. To prevent the impact of blasting loads on civil defense engineering, Wang et al. proposed an empirical formula for stress wave attenuation by adding different loose gravel bodies to the propagation medium [11].

Some studies have shown that the geometric parameters among rock particles have an important effect on the attenuation of stress waves. For example, Li et al. found that with the increase of the roughness of the rock mass, the energy absorption rate increased obviously [12]. Perino et al. obtained a simplified stress wave propagation equation by considering the stress wave reflection effect [13]. Jin et al. studied the propagation of stress waves in sandstones under the confining pressure conditions [14]. Dehghanipoodeh et al. found that the deformation modulus of loose and broken rock under the dynamic load was higher than that under the static load [15]. Mohammadi et al. studied the influence of scattered gravel bodies on the law of seismic wave propagation under impact loads and they found that the simulation results fitted well with the measured data [16]. Zhang et al. found that the higher the degree of fragmentation of the rock mass, the more complex the frequency components of stress waves through the field experiments $[17,18]$. Li et al. found that the filling thickness in sandstone had a significant effect on the propagation of stress waves [19]. The above studies have analyzed the influence of loose gravels on the law of stress wave propagation, but there are no judgment indicators for the cushion height and the number of impacts. The influence of the porosity of loose gravel deposits on the propagation law of vibration speed needs further study.

In this study, demolition of the $180 \mathrm{~m}$ high chimney (Jiaozuo Huarun power plant in China) by directional blasting and the parts of the chimney falling to the ground were regarded as the vibration sources; three kinds of particle sizes of the graded crushed stones were used to construct a loose accumulation body with a right-angled 
trapezoidal cross section with a thickness of 3-6 m. By comparing the theoretical calculated values with the field measured values, the attenuation rules of the vibration energy and vibration velocity were analyzed.

The remainder of this study is organized as follows. In Section 3, the engineering background, the blasting demolition of the chimney and the preparation methods of loose gravel accumulation body are described. In Section 4 , the attenuation rule of blasting vibration velocity is analyzed and that of the energy consumption of touchdown vibration is analyzed also. Finally, some conclusions are given in Section 5.

\section{METHODOLOGY}

\subsection{Engineering Background}

The reinforced concrete chimney of Jiaozuo Huarun Power Plant was located in the west suburb of Jiaozuo city, which had a height of $180 \mathrm{~m}$. It needed to be shut down due to the government's elimination of outdated power plants. As shown in Fig. 1, the air compressor room was located $10 \mathrm{~m}$ east of the chimney, the north and south sides of which were connected to the flue and was $8 \mathrm{~m}$ away from the induced draft fan, respectively. The ash outlet was 27 $\mathrm{m}$ at the west side of the chimney, the swimming pool and gymnasium were at $80 \mathrm{~m}$ away from that, and its surrounding environment was complex.

Due to site restrictions, the chimney was demolished by directional blasting in two stages. As shown in Fig. 2, the first blasting cut was located at the inspection platform provided by the chimney at an elevation of $93 \mathrm{~m}$. The chimney above this position had a weight of $1366.67 \mathrm{t}$ and with the height of gravity center $128.8 \mathrm{~m}$. The second blasting cut was located at the elevation of $25 \mathrm{~m}$, the chimney had a weight of $2815.9 \mathrm{t}$ and with the height of gravity center $47.06 \mathrm{~m}$ within the range of $93 \mathrm{~m}$.

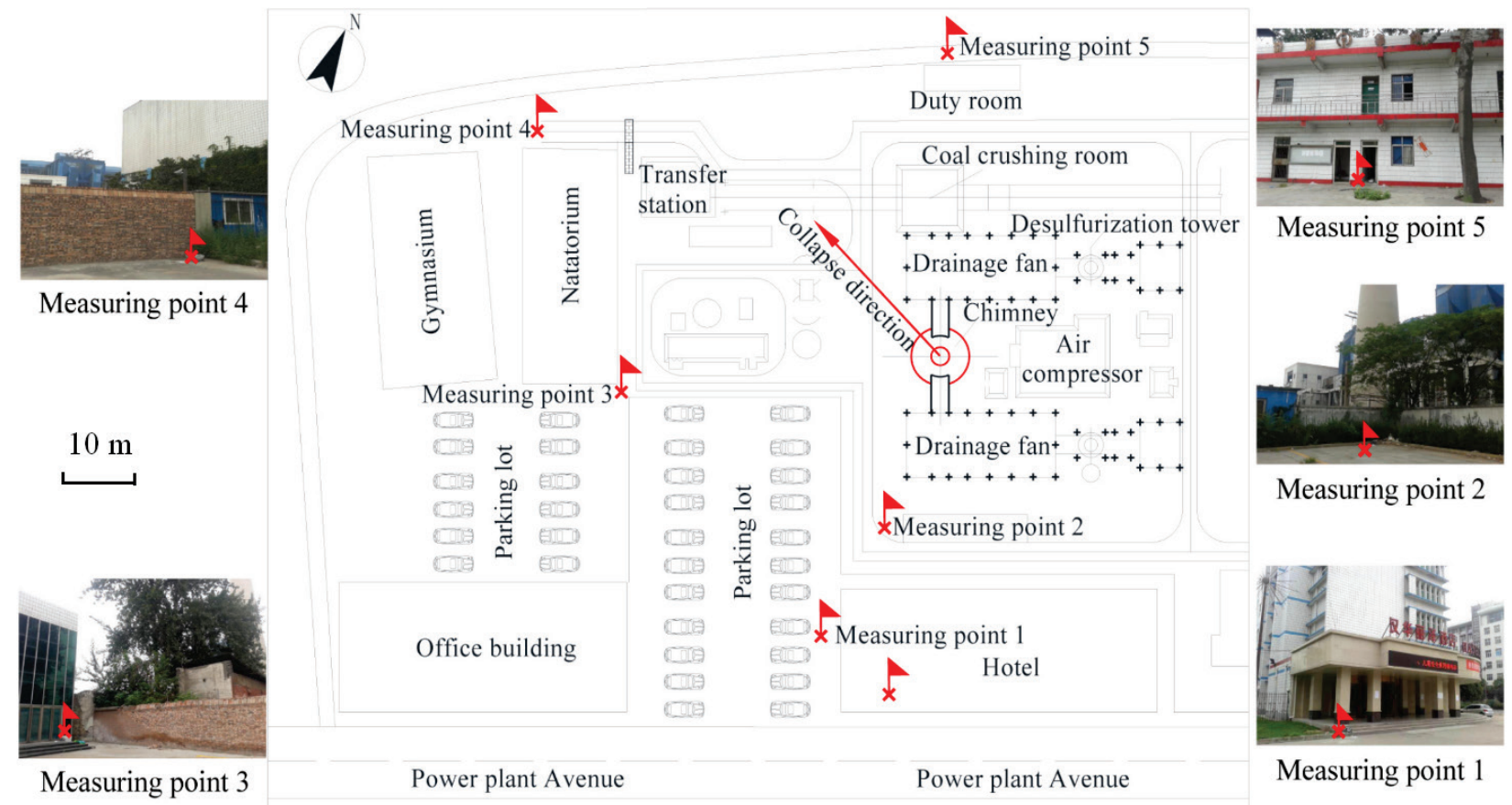

Figure 1 The chimney and its surrounding environment.

\subsection{Monitoring Equipment and Distance Determination}

The instrument type 4850 of vibration monitoring was selected for data acquisition. The vibration resolution of the instrument is $0.0016 \mathrm{~cm} / \mathrm{s}$, whose reading accuracy is $0.5 \%$, and the built-in clock recorded the vibration time automatically. The optional sampling rate is $1-200 \mathrm{kHz}$, two horizontal SC-S type velocity sensors and one vertical C-C type velocity sensor were installed at each monitoring point. The vibration instrument was widely used in vibrations caused by mechanical and blasting activities, which was stable operation and good linearity.

Since the accurate measurement of the distance between the energy generation point and the protection point has an important influence on the results, by means of the special structure of the chimney, the measuring point was set up at the easy observation position of the building to be protected. With the help of the inspection platform of the chimney at the elevation of $93 \mathrm{~m}$, the distance from the building to the protected point was measured by the high precision range finder when the blasting cutting was arranged, and the average value was obtained through the multiple measurements to ensure the accuracy of the test distance.

\subsection{Accumulation Body and Monitoring Points}

The ground medium provided by the on-site environment was a uniform and dense tri-soil. This stratum was low porosity and with the characteristic of slow attenuation of vibration.

To reduce the impact of the vibration velocity caused by the chimney blasting and its touchdown on the ground, within the scope of two times of the diameter of the chimney collapse center line, three kinds of particle sizes of the graded gravel were used to construct a loose gravel accumulation body with the thickness of 3-6 $\mathrm{m}$ and the length of $90 \mathrm{~m}$, which was a right-angled trapezoid 
considering the characteristics of the chimney' collapse and touchdown, as shown in Fig. 2. The loose accumulation body had the characteristics of disordered accumulation, clear edges and corners, irregular shape, more particle grading, and large porosity.

For demolition of the chimney, before each blasting, the monitoring points of vibration velocity were set near the buildings to be protected. There were five monitoring points set for each blasting. There were one vertical and two horizontal directions of the magneto electric sensors being set for each monitoring point at the same time. The location of each monitoring point was shown in Fig. 1.

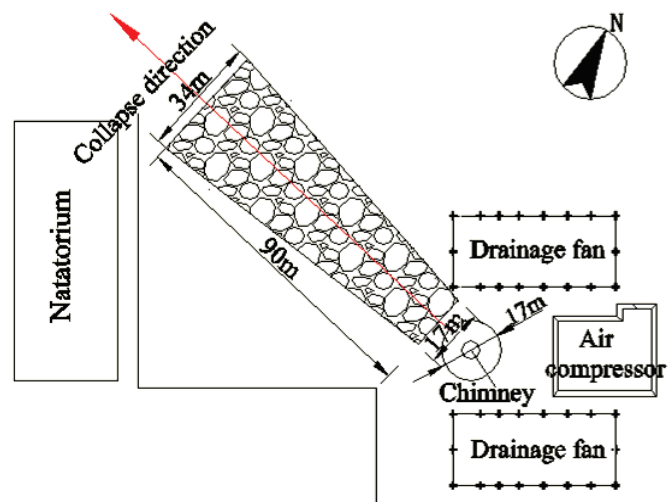

(a) Overlooking of the accumulation body and the chimney

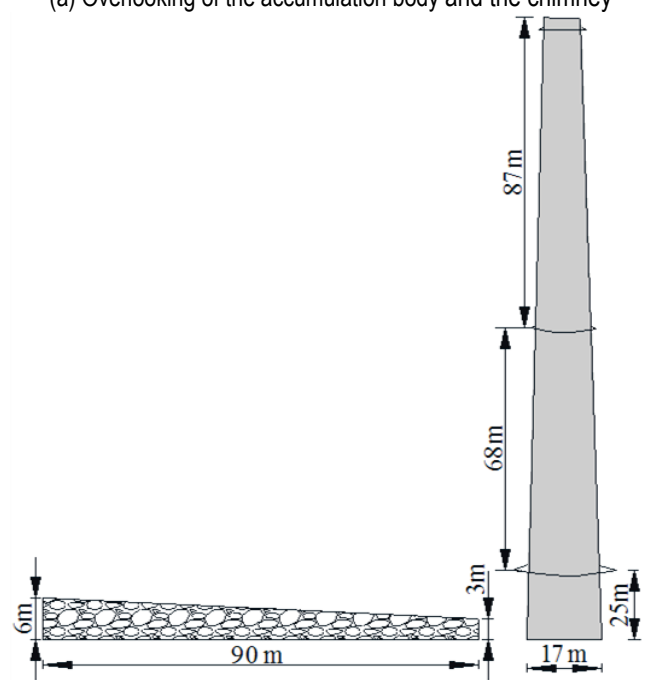

(b) Side view of the accumulation body and the chimney

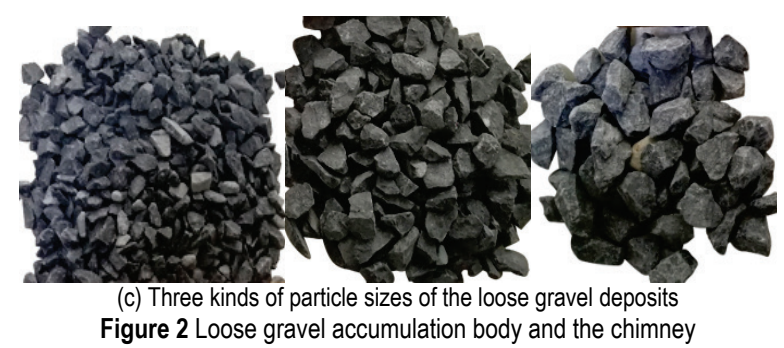

\section{RESULTS AND DISCUSSION}

\subsection{Attenuation Rules of Blasting Vibration Velocity}

Vibration velocity attenuation of the first blasting. The shock wave generated by blasting was converted into stress wave, which was received by the vibration meter in form of velocity. For the influence of blasting vibration on the surrounding buildings, there was no generally accepted theoretical calculation method that conformed to the engineering practice. Generally, the maximum vibration velocity of the particle after blasting was used as the safety criterion, and the velocity of the particle was calculated by Eq. (1) of Sadovsky [20].

For the first blasting, which range is $93-180 \mathrm{~m}$ height of the chimney, with the dead weight of $1365.67 \mathrm{t}$ and the height of the gravity center $128.8 \mathrm{~m}$. The total charge of the first blasting is $44.59 \mathrm{~kg}$ and the maximum charge of single section is $17.78 \mathrm{~kg}$.

$V=K\left(\frac{\sqrt[3]{Q}}{R}\right)^{\alpha}$

where: $V$ is the particle vibration velocity, $\mathrm{cm} / \mathrm{s} ; R$ is the distance between the protected object and blasting point, $\mathrm{m} ; Q$ is the maximum charge of a single section, $\mathrm{kg} ; K$ is the coefficient and $\alpha$ is the attenuation index. The propagation medium between the blasting point and the protected object, according to the experience, is generally taken as $K=50$ and $\alpha=1.6$.

The theoretical values of the vibration velocity of each particle were obtained by substituting the related data into Eq. (1). Combining with the field measured values, the listed results after sorting are shown in Tab. 1.

It can be seen from Fig. 3, the maximum difference between the calculated value and the monitored value of the particle vibration velocity is $0.025 \mathrm{~cm} / \mathrm{s}$. Compared with the allowable vibration velocity of $2.5-3.5 \mathrm{~cm} / \mathrm{s}$ for the general commercial buildings, the error rate caused by the maximum difference is $0.71-1.0 \%$. At the same time, it is found that the attenuation rule of the particle vibration velocity obtained by the theoretical calculation and the monitoring points shows a power function relationship, although the measured value of vibration velocity has a certain discreteness.

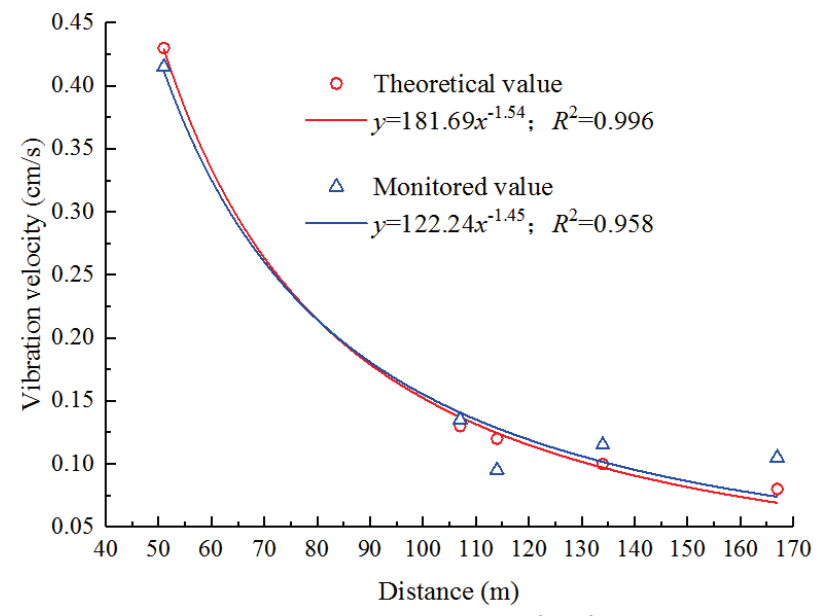

Figure 3 The particle vibration velocity of the first blasting

Vibration velocity attenuation of the second blasting. Due to the limitations of the surrounding environment, to achieve the goal of safety demolition, the second blasting interval is $25-93 \mathrm{~m}$ of the chimney, with the dead weight of $2815.9 \mathrm{t}$ and the height of gravity center $47.06 \mathrm{~m}$. The total charge of the second blasting is 118.2 $\mathrm{kg}$, and the maximum charge of single section is $49.92 \mathrm{~kg}$.

The theoretical values of the vibration velocity of each particle were obtained by substituting the related data into 
Eq. (1). Combining with the field measured values, Tab. 2 listed the obtained results after sorting.

As seen from Fig. 4, the maximum difference between the calculated value and the measured value of the particle vibration velocity is $0.035 \mathrm{~cm} / \mathrm{s}$. Compared with the allowable vibration velocity of $2.5-3.5 \mathrm{~cm} / \mathrm{s}$ for the general commercial buildings, the error rate caused by the maximum difference is $1.0-1.4 \%$. It is found that the attenuation rule of the particle vibration velocity obtained by theoretical calculation and the monitoring points shows a power function relationship also.

Table 1 Comparison values of vibration velocity of the first blasting

\begin{tabular}{|c|c|c|c|c|}
\hline No. & $\begin{array}{c}\text { Location of monitoring } \\
\text { points }\end{array}$ & Distance from chimney / m & $\begin{array}{c}\text { Theoretical value of vibration } \\
\text { velocity / cm/s }\end{array}$ & $\begin{array}{c}\text { Measured maximum value of vibration } \\
\text { velocity / cm/s }\end{array}$ \\
\hline 1 & Hotel & 114 & 0.12 & 0.095 \\
\hline 2 & Staff restaurant & 51 & 0.43 & 0.415 \\
\hline 3 & Southeast of natatorium & 107 & 0.13 & 0.135 \\
\hline 4 & Northwest of natatorium & 167 & 0.08 & 0.105 \\
\hline 5 & Duty room & 134 & 0.10 & 0.115 \\
\hline
\end{tabular}

Table 2 Comparison values of vibration velocity of the second blasting

\begin{tabular}{|c|c|c|c|c|}
\hline No. & $\begin{array}{c}\text { Location of monitoring } \\
\text { points }\end{array}$ & Distance from chimney / m & $\begin{array}{c}\text { Theoretical value of vibration } \\
\text { velocity / cm/s }\end{array}$ & $\begin{array}{c}\text { Measured maximum value of vibration } \\
\text { velocity / cm/s }\end{array}$ \\
\hline 1 & Hotel & 114 & 0.21 & 0.195 \\
\hline 2 & Staff restaurant & 51 & 0.74 & 0.715 \\
\hline 3 & Southeast of natatorium & 107 & 0.23 & 0.275 \\
\hline 4 & Northwest of natatorium & 167 & 0.11 & 0.145 \\
\hline 5 & Duty Room & 134 & 0.16 & 0.175 \\
\hline
\end{tabular}



Figure 4 The particle vibration velocity of the second blasting

The calculated value of the blasting vibration velocity in this study fitted well with the measured value, which was within an acceptable range. The results showed that the medium was relatively uniform in the range of all monitoring points, and it also proved the reliability of the vibration monitoring instrument, which also provided the reliability for the subsequent analysis of the touchdown vibration of the parts of the chimney falling to the ground.

\subsection{Attenuation Rules and Energy Consumption Analysis of Touchdown Vibration}

The chimney was blasted twice in two sections, accompanied by two touchdowns. There were also five monitoring points set for each touchdown vibration, as shown in Fig. 1.

Attenuation rules of the first touchdown vibration velocity. Compared with the blasting vibration, the touchdown vibration has the characteristics of large energy, high vibration velocity, low frequency and long action time. Since the natural frequency of the general buildings is between $3-10 \mathrm{~Hz}$, the main frequency range of the touchdown vibration is generally lower than $10 \mathrm{~Hz}$, which belongs to the low frequency vibration and is close to the fundamental frequency of the building [22]. The touchdown vibration could cause large dynamic response of the surrounding structure or cause resonance phenomenon. Without artificial control, the surrounding buildings would be damaged irreparably. Meanwhile, the vibration wave beyond the main frequency range of the building is called high frequency vibration, which is easy to be attenuated in the process of propagation and generally does not cause great damage to the building. At present, the particle vibration velocity caused by the touchdown was generally analyzed according to Eq. (2) [21].

$V_{\mathrm{t}}=k_{\mathrm{t}}\left[\frac{R_{2}}{(2 M g H / \sigma)^{1 / 3}}\right]^{\beta}$

where: $V_{\mathrm{t}}$ is the vibration velocity of the touchdown, $\mathrm{cm} / \mathrm{s}$; $k_{\mathrm{t}}$ is the attenuation coefficient of the touchdown vibration, which is generally taken as $k_{\mathrm{t}}=5.37-4.09 ; M$ is the weight of touchdown object, $\mathrm{t} ; g$ is the acceleration of gravity, $\mathrm{m} / \mathrm{s}^{2} ; H$ is the height of gravity center of the building, $\mathrm{m} ; \sigma$ is the failure strength of the ground medium, which is generally taken as $\sigma=10 \mathrm{MPa} ; R_{2}$ is the distance from the vibration monitoring point to the touchdown position, $\mathrm{m}$.

When the first touchdown vibration occurred, the parameters related to the touchdown vibration were the dead weight of chimney $1365.67 \mathrm{t}$ with the height of gravity center $128.8 \mathrm{~m}$. Substituting the related data into Eq. (2), the theoretical value of the vibration velocity of each particle could be obtained. Combining with the monitored values, Tab. 3 listed the obtained results after sorting.

As can be seen from Fig. 5 and Tab. 3, the monitored values of the particle vibration velocity after the action of the loose gravel accumulation are far less than the maximum and minimum values of the theoretical calculation and the maximum allowable vibration velocity of the buildings. To ensure the reliability and accuracy of analysis, only the minimum values of the theoretical calculation were compared with the monitoring values. 
The maximum attenuation range of the particle vibration velocity is $2.2 \mathrm{~cm} / \mathrm{s}$ at the monitoring point 2 , and the attenuation rate is $68.11 \%$. The minimum attenuation range of that is $0.75 \mathrm{~cm} / \mathrm{s}$ at monitoring point 1 , and the attenuation rate is $77.32 \%$. The average attenuation range of the five monitoring points is $1.45 \mathrm{~cm} / \mathrm{s}$, and the average attenuation rate is $70.75 \%$.

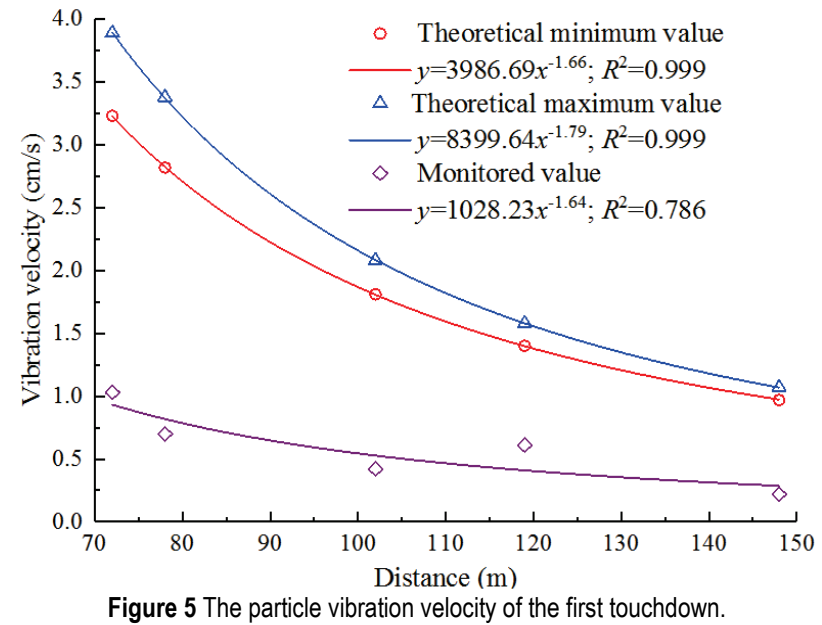

It can be seen from Fig. 5, the monitored values of the particle vibration velocity are obviously smaller than the theoretical value under the action of the loose gravel accumulation body. The theoretical values of the vibration velocity and the monitoring points show the power function relationship from near to far.

Attenuation rules of the second touchdown vibration velocity. When the second touchdown vibration occurred, the parameters related to the touchdown vibration velocity were the dead weight of chimney 2815.9 $\mathrm{t}$ and the height of gravity center $47.06 \mathrm{~m}$. Substituting the related data into Eq. (2), the theoretical value of the vibration velocity of each particle was obtained. Combining with the monitored values, Tab. 4 listed the obtained results after sorting.
It can be seen from Fig. 6 and Tab. 4, the monitored values of the particle vibration velocity after the action of loose gravel accumulation body are far less than the maximum and minimum values of the theoretical calculation and the maximum allowable vibration velocity of the buildings. Only the minimum values of the theoretical calculation were compared with the monitored values. The maximum attenuation range of the particle vibration velocity is $1.33 \mathrm{~cm} / \mathrm{s}$ at the monitoring point 2 , and the attenuation rate is $48.19 \%$. The minimum attenuation range of the particle vibration velocity is 0.75 $\mathrm{cm} / \mathrm{s}$ at monitoring point 4 , and the attenuation rate is $17.5 \%$. The average attenuation range of the five monitoring points is $0.68 \mathrm{~cm} / \mathrm{s}$, and the average attenuation rate is $35.35 \%$.

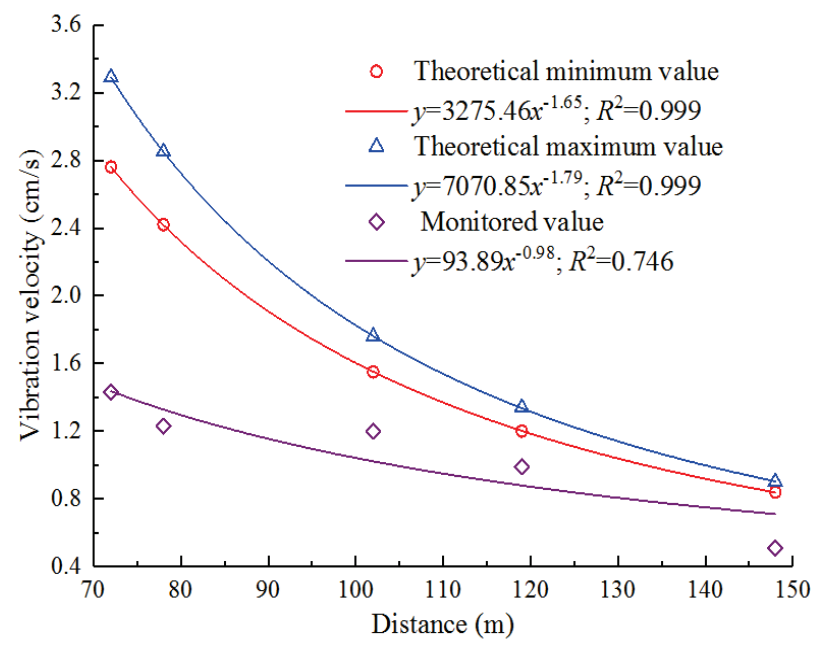

Figure 6 The particle vibration velocity of the second touchdown

It can be seen from Fig. 6, the monitored values of the particle vibration velocity are obviously smaller than the theoretical values under the action of the loose gravel accumulation body. The theoretical values of the vibration velocity and the monitoring points show the power function relationship from near to far.

Table 3 Comparison values of vibration velocity of the first touchdown

\begin{tabular}{|c|c|c|c|c|c|}
\hline No. & Location of monitoring points & $\begin{array}{l}\text { Distance from } \\
\text { chimney / m }\end{array}$ & $\begin{array}{l}\text { Theoretical value of } \\
\text { vibration velocity } / \mathrm{cm} / \mathrm{s}\end{array}$ & $\begin{array}{l}\text { Measured maximum value of } \\
\text { vibration velocity } / \mathrm{cm} / \mathrm{s}\end{array}$ & $\begin{array}{l}\text { Main vibration } \\
\text { frequency / Hz }\end{array}$ \\
\hline 1 & Hotel & 148 & $0.97-1.07$ & 0.22 (horizontal tangential) & 7.3 \\
\hline 2 & Staff restaurant & 72 & $3.23-3.89$ & 1.03 (horizontal tangential) & 7.1 \\
\hline 3 & Southeast of natatorium & 78 & $2.82-3.38$ & 0.70 (horizontal tangential) & 4.0 \\
\hline 4 & Northwest of natatorium & 119 & $1.40-1.58$ & 0.61 (horizontal tangential) & 4.0 \\
\hline 5 & Duty Room & 102 & $1.81-2.08$ & 0.42 (horizontal tangential) & 3.0 \\
\hline
\end{tabular}

Table 4 Comparison values of vibration velocity of the second touchdown

\begin{tabular}{|c|c|c|c|c|c|}
\hline No. & Location of monitoring points & $\begin{array}{c}\text { Distance from } \\
\text { chimney / m }\end{array}$ & $\begin{array}{c}\text { Theoretical value of } \\
\text { vibration velocity / cm/s }\end{array}$ & $\begin{array}{c}\text { Measured maximum value of } \\
\text { vibration velocity / cm/s }\end{array}$ & $\begin{array}{c}\text { Main vibration } \\
\text { frequency / Hz }\end{array}$ \\
\hline 1 & Hotel & 148 & $0.84-0.90$ & 0.51 (horizontal tangential) & 10.0 \\
\hline 2 & Staff restaurant & 72 & $2.76-3.29$ & 1.43 (horizontal tangential) & 7.0 \\
\hline 3 & Southeast of natatorium & 78 & $2.42-2.85$ & 1.23 (horizontal tangential) & 5.9 \\
\hline 4 & Northwest of natatorium & 119 & $1.20-1.34$ & 0.99 (horizontal tangential) & 10.8 \\
\hline 5 & Duty Room & 102 & $1.55-1.76$ & 1.20 (horizontal tangential) & 3.0 \\
\hline
\end{tabular}

Taking the touchdown as the vibration source, when the parts of the chimney were in contact with the loose gravel accumulation body, its strong impact kinetic energy was transformed into the stress wave in a short time and propagated to the distance. Due to the loose gravel accumulation body had the characteristics of high randomness, large particle size distribution, different filling degree and filling materials, the impact of the touchdown vibration on the surrounding environment was greatly reduced.

The dimensionless analysis of the velocity attenuation factor of the touchdown vibration is as follows. 
$\omega=\frac{v_{\mathrm{m}}-v_{\mathrm{s}}}{v_{\mathrm{m}}}$

where: $\sigma$ is the attenuation rate of the touchdown vibration; $v_{\mathrm{m}}$ is the theoretical minimum value of the particle vibration velocity caused by the touchdown, $\mathrm{cm} / \mathrm{s} ; v_{\mathrm{s}}$ is the monitored value of the particle vibration velocity caused by the touchdown, $\mathrm{cm} / \mathrm{s}$.

Under the action of the two touchdowns, the maximum difference of the vibration velocity attenuation rate occurs at the monitoring point 3 , which is $54.21 \%$. The minimum difference of that occurred at the monitoring point 2 which is $19.92 \%$. The average difference is $35.41 \%$. As seen from Fig. 7, the variety of the velocity attenuation rate caused by the two touchdown vibrations was approximately the same under the action of loose gravel accumulation body. The attenuation rate of the second touchdown vibration is obviously smaller than that of the first one. Due to the first touchdown, the original loose gravel accumulation body became relatively dense and the porosity was significantly reduced, which resulted in the reduction of the energy absorption rate when the second touchdown vibration occurred.

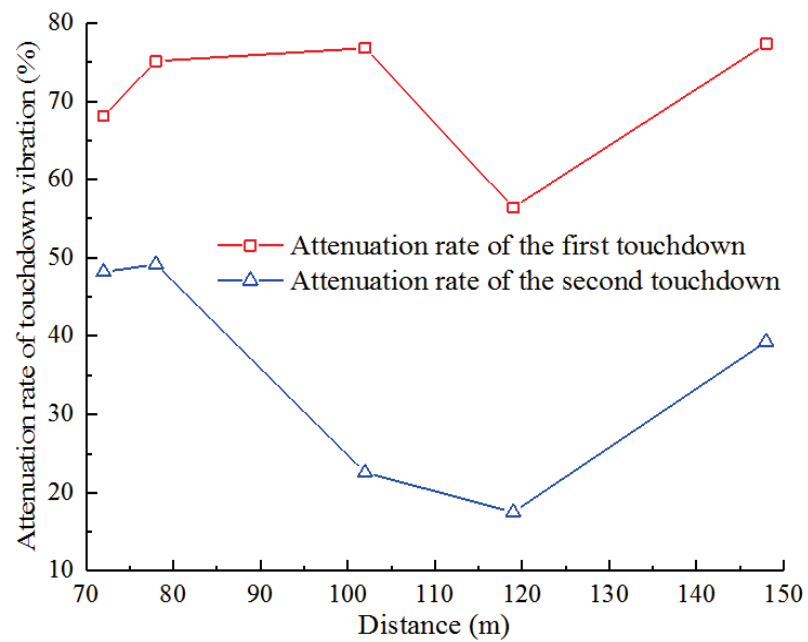

Figure 7 The attenuation rate of the particle vibration velocity under two touchdowns

\subsection{Energy Dissipation Effect of Loose Gravel Accumulation Body}

In the process of the building collapse and touchdown, the energy coefficient of touchdown kinetic energy is $\eta_{\mathrm{k}}$, the related formula is as follows:

$$
\begin{aligned}
& E_{\mathrm{k}}=\eta_{\mathrm{k}} E_{0} \\
& \frac{1}{2} m v^{2}=\eta_{\mathrm{k}} m g h
\end{aligned}
$$

where: $E_{\mathrm{k}}$ is the touchdown kinetic energy, $\mathrm{J} ; E_{0}$ is the total potential energy before the building instability, $\mathrm{J} ; m$ is the touchdown weight of the building, $\mathrm{kg}$; $v$ is the touchdown velocity, $\mathrm{cm} / \mathrm{s} ; g$ is the acceleration of gravity, $\mathrm{m} / \mathrm{s}^{2} ; h$ is the height of gravity center before the building loses stability, $\mathrm{m}$.
The energy dissipation of the parts of the chimney in contact with the loose gravel accumulation body could be divided into three components: the first one deformed the loose gravel accumulation body, the second one made the loose gravel accumulation body react to the touchdown energy, the third one produced the stress wave and propagated to the distance continuously. During the process of touchdown, the energy was conserved. If the transformed energy coefficient is $\beta$, then

$\frac{1}{2} \beta m v^{2}=\frac{1}{2} m v^{2}+\frac{1}{2} M_{\mathrm{d}} v_{\mathrm{d}}^{2}$

where: $v$ is the reaction velocity of the loose gravel accumulation body to the chimney, $\mathrm{cm} / \mathrm{s} ; v_{\mathrm{d}}$ is the velocity obtained by the loose gravel accumulation body, $\mathrm{cm} / \mathrm{s} ; M_{\mathrm{d}}$ is the weight of the loose gravel accumulation body, $\mathrm{kg}$.

The energy difference between the particle vibration velocity of the theoretical value and the monitored value could be regarded as the energy absorbed by the loose gravel accumulation body. As can be seen from Fig. 8, the energy absorption rate of the first touchdown of the loose gravel accumulation body is greater than that of the second. The minimum value of the theoretical calculation and the monitored value are selected for comparison.



Figure 8 Comparison of energy consumption of two touchdowns by loose grave accumulation

When the first touchdown occurred, the maximum value of the energy absorption was $4.7 \times 10^{7} \mathrm{~J}$ at the monitoring point 2 . The minimum value was $0.446 \times 10^{7} \mathrm{~J}$ at the monitoring point 1 , and the average energy absorption was $2.24 \times 10^{7} \mathrm{~J}$. When the second touchdown occurred, the maximum value of the energy absorption was $2.79 \times 10^{7} \mathrm{~J}$ at the monitoring point 2 , the minimum value was $0.22 \times 10^{7} \mathrm{~J}$ at the monitoring point 1 , and the average energy absorption was $1.18 \times 10^{7} \mathrm{~J}$. The energy absorption of the first touchdown by the loose gravel accumulation body was about 1.89 times that of the second touchdown. Due to the effect of the first touchdown, the original loose gravel accumulation body became relatively dense and the porosity was significantly reduced, which resulted in the reduction of the energy absorption rate when the second touchdown vibration occurred.

The impact action of the chimney touchdown on the loose gravel accumulation body could be expressed as Eq. (7) 
without considering the crushing and a small amount of springback.

$$
\int_{0}^{\mathrm{t}} P_{\mathrm{c}} \mathrm{d} t=m_{\mathrm{c}} v_{0}
$$

where: $v_{0}$ is the velocity at the moment of the touchdown, $\mathrm{cm} / \mathrm{s} ; t$ is the action time between the touchdown object and the loose gravel accumulation body, $\mathrm{s} ; P_{\mathrm{c}}$ is the impact force of the touchdown object, $\mathrm{kN} ; m_{\mathrm{c}}$ is the weight of the touchdown object, $\mathrm{kg}$. The touchdown object is divided into several elements, $P_{\mathrm{c}}, m_{\mathrm{c}}$ and $v_{0}$ are all functions of the location of these different elements. If the positions of the different elements are fixed, then $m_{\mathrm{c}}$ and $v_{0}$ are constants. Therefore, the shorter the touchdown action time $t$ is, the greater the impact force $P_{\mathrm{c}}$ is. The loose gravel accumulation body is to prolong the touchdown action time and reduce the touchdown energy.

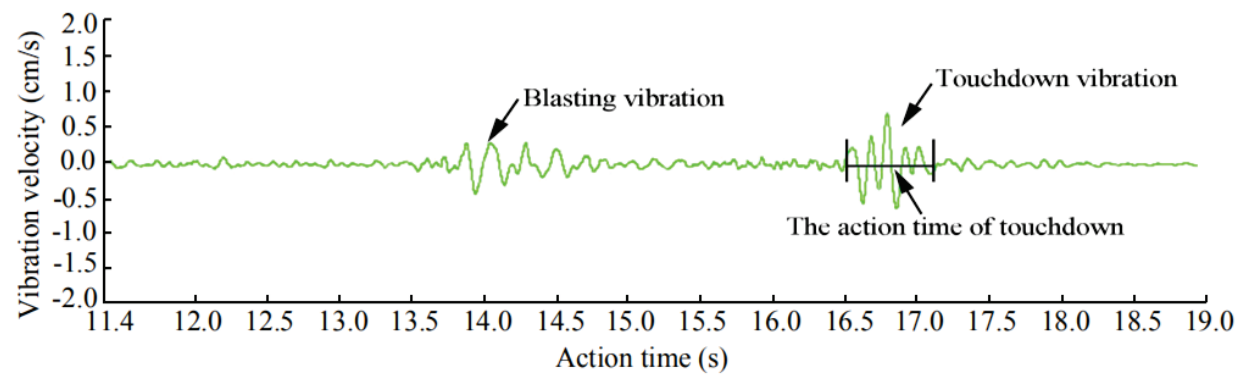

(a) The vibration velocity of the first blasting at monitoring point 3

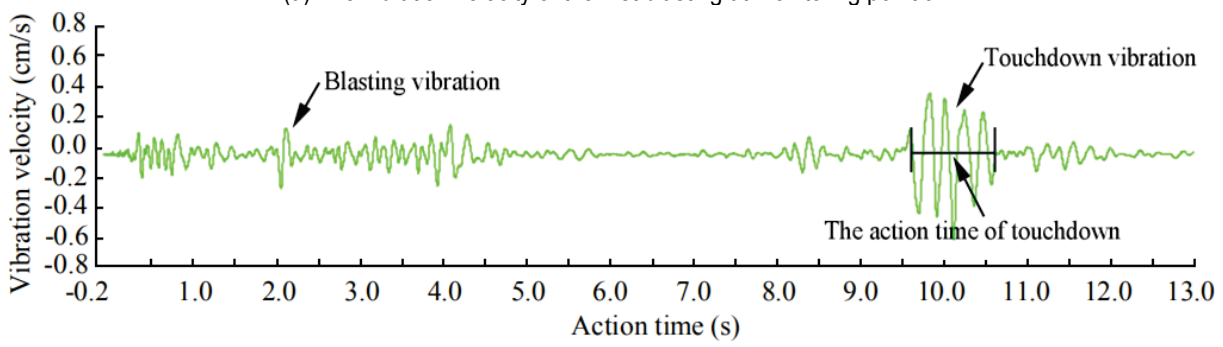

(b) The vibration velocity of the second blasting at monitoring point 1



(c) The vibration velocity of the second blasting at monitoring point 4

Figure 9 The monitored values of the particle vibration velocity

Dimensionless analysis of the attenuation rate of the touchdown energy is as follows.

$\xi=\frac{E_{\mathrm{m}}-E_{\mathrm{s}}}{E_{\mathrm{m}}}$

where, $\xi$ is the energy attenuation rate of the touchdown; $E_{\mathrm{m}}$ is the theoretical minimum value of the particle vibration energy, $\mathrm{J} ; E_{\mathrm{s}}$ is the monitored value of the particle vibration energy, $\mathrm{J}$.

It can be seen from Fig. 9, the action time of the parts of the chimney touchdown and the loose gravel accumulation body is about $0.7-1.0 \mathrm{~s}$. As seen from Fig. 10, the average energy absorption rate of the first touchdown and the second touchdown is $90.4 \%$ and $56.4 \%$, respectively. The energy absorption rate would increase with the prolonged action time, but it would not continue to increase. The energy absorption rate would gradually decrease with the touchdown times increasing, until which reaching a certain stable value.

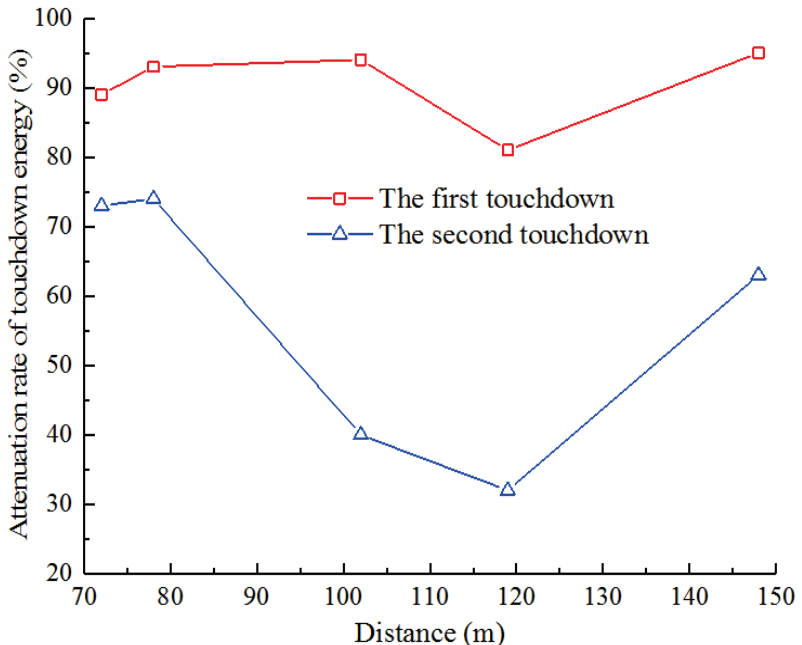

Figure 10 The energy attenuation rate of each monitoring point under two touchdowns 


\section{CONCLUSION}

Taking the loose gravel deposits as the cushion layer to reduce the touchdown vibration, the velocity of the blasting vibration and the touchdown vibration of the parts of the chimney falling to the ground were calculated and monitored, the main conclusions are as follows:

(1) During the process of the blasting demolition of chimney, the attenuation rules of the vibration velocity from near to far display a power function with negative exponent. The difference between the theoretical and the monitored values of the two blasting vibration velocities is small, which confirms the reliability of the selected monitoring instrument.

(2) For the parts of the chimney collapse and touchdown, the attenuation rules of the vibration velocity show the highest correlation with the distance as a power function. After laying 3-6 $\mathrm{m}$ thick loose gravel accumulation body, the action time of touchdown is prolonged by $0.7-1.0 \mathrm{~s}$, the average velocity attenuation rate of the first touchdown vibration is $70.75 \%$, and that of the second one is $35.35 \%$.

(3) Compared with the attenuation characteristics of the two touchdown vibrations through the dimensionless analysis, the energy absorption rate decreases gradually with the increase of the touchdown times, and the energy absorption rate of the first touchdown vibration is about 1.61 times of that of the second touchdown.

Considering the influence of various factors on the vibration velocity and energy consumption, how to select the suitable filling materials as the cushion layer needs further study to reduce the touchdown vibration of the blasting demolition buildings in the future.

\section{Acknowledgements}

This study was financially supported by the National Natural Science Foundation of China (51774112), the International Cooperation Project of Henan Science and Technology Department (182102410060), the Doctoral Fund of Henan Polytechnic University (B2015-67).

\section{REFERENCES}

[1] De, A., Morgante, A. N., \& Zimmie, T. F. (2016). Numerical and physical modeling of geofoam barriers as protection against effects of surface blast on underground tunnels. Geotextiles and Geomembranes, 44(1), 1-12. https://doi.org/10.1016/j.geotexmem.2015.06.008

[2] Song, X. R., Huang, C. L., Zhang, G. F., Shan, W. C., \& Wang, Y. M. (2019). Experimental study on seismic performance of new-type composite shear wall. DYNA, 94(4), 465-472. https://doi.org/10.6036/9192

[3] Mohtarami, E., Baghbanan, A., Akbariforouz, M., Hashemolhosseini, H., \& Asadollahpour, E. (2018). Chemically dependent mechanical properties of natural andesite rock fractures. Canadian Geotechnical Journal, 55(6), 881-893. https://doi.org/10.1139/cgj-2016-0626

[4] Wang, S. R., Shi, K. P., Li, Z. H., Li, Z. C., \& Wang, Y. F. (2019). Spatial distribution law of vibration acceleration of ultra-small-spacing tunnel under train moving loads. Journal of Engineering Science and Technology Review, 12(6), 96104. https://doi.org/10.25103/jestr.126.12
[5] Bose, T., Choudhury, D., Sprengel, J., \& Ziegler, M. (2018). Efficiency of open and infill trenches in mitigating groundborne vibrations. Journal of Geotechnical and Geoenvironmental Engineering, 144(8), 1-11. https://doi.org/10.1061/(ASCE)GT.1943-5606.0001915

[6] Majumder, M. \& Ghosh, P. (2016). Intermittent geofoam infilled trench for vibration screening considering soil nonlinearity. KSCE Journal of Civil Engineering, 20(6), 23082318. https://doi.org/10.1007/s12205-015-0267-6

[7] Azzam, W. R., Ayeldeen, M., \& Siragy, M. E. (2018). Improving the structural stability during earthquakes using in-filled trench with EPS geofoam-numerical study. Arabian Journal of Geosciences, Article, 11, 1-11. https://doi.org/10.1007/s12517-018-3739-4

[8] Vivek, P. \& Sitharam, T. G. (2017). Shock wave attenuation by geotextile encapsulated sand barrier systems. Geotextiles and Geomembranes, 45(3), 149-160. https://doi.org/10.1016/j.geotexmem.2017.01.006

[9] Yu, X., Chen, L., Fang, Q., Zhang, J. H., Guo, D., \& Hou, X. F. (2019). Determination of attenuation effects of coral sand on the propagation of impact-induced stress wave. International Journal of Impact Engineering, 125, 63-82. https://doi.org/10.1016/j.jijmpeng.2018.11.004

[10] Rafiee-Dehkharghani, R., Aref, A. J., \& Dargush, G. F. (2015). Planar stress wave attenuation in plates with circular voids and inclusions. Composites Part B: Engineering, 75, 307-318. https://doi.org/10.1016/j.compositesb.2015.01.051

[11] Wang, Z. L., Li, Y. C., \& Wang, J. G. (2006). Numerical analysis of attenuation effect of EPS geofoam on stresswaves in civil defense engineering. Geotextiles and Geomembranes, 24(5), 265-273. https://doi.org/10.1016/j.geotexmem.2006.04.002

[12] Li, J. C., Rong, L. F., Li, H. F., \& Hong, S. N. (2019). An SHPB test study on stress wave energy attenuation in jointed rock masses. Rock Mechanics and Rock Engineering, 52(2), 403-420. https://doi.org/10.1007/s00603-018-1586-y

[13] Perino, A., Zhu, J. B., Li, J. C., Barla, G. B., \& Zhao, J. (2010). Theoretical methods for wave propagation across jointed rock masses. Rock Mechanics and Rock Engineering, 43(6), 799-809. https://doi.org/10.1007/s00603-010-0114-5

[14] Jin, J. F., Wang, J., Guo, Z. Q., Liang, C., Yuan, W., Wu, Y., Zhang, R., \& Wang, X. B. (2019). Influence of confining pressure on stress wave propagation characteristics in red sandstone. Journal of China Coal Society, 44 (2), 435-444.

[15] Dehghanipoodeh, M., Baghbanan, A., Hashemolhosseini, H., Laghaei, M., \& Salimian, M. H. (2019). Investigating the deformability of grouted rock mass under static and dynamic loading conditions. Bulletin of Engineering Geology and the Environment, 78(6), 4549-4566. https://doi.org/10.1007/s10064-018-1414-3

[16] Mohammadi, H. R., Mansouri, H., Bahaaddini, M., \& Jalalifar, H. (2017). Investigation into the effect of fault properties on wave transmission. International Journal for Numerical and Analytical Methods in Geomechanics, 41(17), 1741-1757. https://doi.org/10.1002/nag.2698

[17] Zhang, S. H., Liu, L. S., Zhong, Q. L., Qiu, J. M., \& Zhong, W. (2019). Energy distribution characteristics of blast seismic wave on open pit slope. Journal of Vibration and Shock, 38 (7), 224-232.

[18] Wang, S. R., Shi, K. P., He, Y. S., \& Wang, X. Q. (2019). Dynamic response analysis of middle pillar for ultra-small spacing tunnels under train vibration loads. Journal of Engineering Science and Technology Review, 12(3), 30-37.

[19] Li, X. F., Li, H. B., Li, J. C., \& Li, Z. W. (2018). Research on transient wave propagation across nonlinear joints filled with granular materials. Rock Mechanics and Rock Engineering, 51, 2373-2393. https://doi.org/10.1007/s00603-018-1471-8

[20] Liu, D., Lu, W. B., Chen, M., \& Yan, P. (2018). Attenuation formula of the dominant frequency of blasting vibration 
during tunnel excavation. Chinese Journal of Rock Mechanics and Engineering, 37(9), 2015-2026.

[21] Yang, Y. Q., Hu, J. J., Xie, L. L., \& Wu, X. H. (2016) Characteristics of ground vibration velocity in viaduct blasting demolition. Journal of Vibration and Shock, 35(11), 151-154.

[22] Song, X. R., Huang, C. L., Zhang, G. F., Shan, W. C., \& Wang, Y. M. (2019). Experimental study on seismic performance of new-type composite shear wall. DYNA, 94(4), 465-472. https://doi.org/10.6036/9192

\section{Contact information:}

Shuren WANG, PhD, Professor

(Corresponding author)

International Joint Research Laboratory of Henan Province for Underground,

Space Development and Disaster Prevention, Henan Polytechnic University,

No. 2001 Century Avenue, Jiaozuo, Henan Province, 454003, China

E-mail:w_sr88@163.com

Jiyun ZHANG, PhD candidate

School of Civil Engineering, Henan Polytechnic University,

No. 2001 Century Avenue, Jiaozuo, Henan Province, 454003, China

E-mail: 465743184@qq.com

Jingtao LI, Master candidate

School of Civil Engineering, Henan Polytechnic University,

No. 2001 Century Avenue, Jiaozuo, Henan Province, 454003, China

E-mail:13733743865@163.com

Fuli KONG, ME, Assistant Professor

Institute of National Defense Engineering, Academy of Military Sciences,

No. 3 Xishan Road, Luoyang, Henan Province, 471023, China

E-mail: kfllyss@163.com

Junqi FAN, PhD, Associate Professor

Institute of National Defense Engineering, Academy of Military Sciences,

No. 3 Xishan Road, Luoyang, Henan Province, 471023, China

E-mail: Iyfjq@163.com 